\title{
DEL OCCIDENTE DE LA PENÍNSULA IBÉRICA ${ }^{1}$
}

\section{PORTUGUÉS ESTIAR}

Los diccionarios portugueses, lo mismo etimológicos (NASCENtes) que usuales (Moraes, Caldas Aulete, Figuerredo), y también el $R E W(248)$ consideran al verbo portugués estiar como un derivado de estio. Me temo que en las definiciones de estiar (¿y hasta qué punto en el uso?) haya influído también esa intuición etimológica tan al alcance de la mano (y sin embargo, como vamos a ver, equivocada).

Consignemos desde ahora algunas definiciones corrientes que en el momento oportuno discutiremos. Figueiredo: "Estiar, v. i. Tornar-se sereno ou sêco (falando-se do tempo). Fig. Afroixar". Contrasta la parquedad de Figuerredo con la abundancia de acepciones en MoRAES (189o): "Passar o mau tempo, serenar; parar de chover: vae estiar; estiou; o tempo estiou; estiou a chuva: ficou o ceu como no estio, sereno. § Abaixar a agua da cheia ou do rio. $\S$ Relaxar, afrouxar". O compárese con Caldas Aulete (2a ed., 1925): "Estiar. Serenar o tempo: «Quando o tempo estiou»(Camillo). / Cessar de chover: «Podes sahir; já estiou». / Abaixar a agua da cheia. / Fig. e des. Relaxar-se, afrouxar".

Vamos a dejar un momento de lado la cuestión de los sentidos y etimología de estiar, para atender a la voz estiagem, que en esos diccionarios (y también para el más inmediato sentido común) ofrece asimismo una etimología demasiado obvia (y también errónea): de estiar + agem. He aquí algunas definiciones de estiagem. Moraes: "O estado de seccura da atmosphera e da terra no estio. Legisl. Mod. $\S$ A continuada falta de chuva. $\S$ Cessação de mau tempo; estiada. $\S$ O abaixamento da agua da cheia ou do rio". Caldas Aulete:

${ }^{1}$ Con objeto de evitar complicaciones tipográficas, empleo siempre la ortografía normal castellana para las voces gallego-asturianas recogidas por mí. Es decir, v. gr., represento por $l l$ la palatal lateral sonora, y con un solo signo, $b$, lo mismo la $b$ oclusiva que la fricativa, todo como en la ortografía castellana (y lo hago así, porque en ese dialecto la $b$ es, ya oclusiva, ya fricativa, en condiciones semejantes a las del castellano). Matizo, en cambio, las vocales tónicas y algunas átonas $(e, e, o, q)$, y uso los signos fonéticos $\check{s}$, para la fricativa prepalatal sorda y $y$ para la nasal velar. Claro que no empleo nunca las letras de la ortografía castellana $v$ y $h$. Estas breves indicaciones -que ampliaré en otro lugar-bastan por ahora para las palabras mencionadas en el presente artículo. 
"(Hydraul.) Maximo abaixamento das aguas de um rio, lago, canal, etc. / O tempo sereno que succede á chuva ou trovoada; tempo sêcco". Figueiredo, también ahora más parco, sólo da la segunda de esas acepciones de Caldas Aulete. Ocurre precisamente que la primera acepción de Caldas Aulete es la única radical, original. Porque el port. estiagem y el esp. estiaje son tecnicismos de hidráulica, de introducción bastante reciente; más aún, son, los dos, extranjerismos, meras adaptaciones del fr. étiage. Nuevo asombro: el fr. étiage no tiene nada que ver con el fr. été (<lat. a e s t a t e m), sino que es una palabra formada en el siglo XviII sobre étier 'chenal allant de la mer à un marais' y 'chenal de moulin'. Etier viene de a e s t u a ri u m (REW, $250)^{2}$, es decir, es, por lo que toca a la etimología, el correspondiente francés (es voz del Oeste) del esp. estero, port. esteiro. El significado de la palabra étiage ("nivel más bajo en el año, de un río, de un lago, etc.') lo mismo que su significante, estaban ya colaborando para que se pensara en $e^{\prime} e^{3}$, sin tener en cuenta que también los hie. los pueden producir étiage ("Le Rhône atteint son étiage en hiver, la Seine en été", Larousse Universel). Fácil es pensar lo que ocurrió al adaptar la voz étiage al español y al portugués: se pensó, naturalmente, en estio y se calcaron así las formas estiaje, estiagem ${ }^{4}$; más aún, la palabra tendió a asociarse con el significado del esp. estio, port. estio, a contagiarse de ese significado. El contagio está patente en Caldas Aulete: "tempo sêcco"; y patentísimo en Moraes con su definición etimológica: "O estado de seccura ... no estio" ". Pero, ¿acaso no se produce lo mismo en la mente de cualquier español o portugués que oye esas voces, estiaje, estiagem? Desde su origen, desde el mismo acto de su nacimiento, fatalmente impulsadas por una cercanía a la par fonética y conceptual, estas palabras peninsulares estaban destinadas a enmarañarse con estio, estio.

${ }^{2}$ Es la etimología aceptada hoy sin discusión, lo mismo que por el $R E W$ por Gamillscheg, Dauzat, $F E W$, etc.

3 También en época pasada se despistaron los etimólogos: LrTrRé derivaba étiage de a estiva t c u m, etimología, como hemos visto en la nota anterior, absolutamente descartada por el estado actual del conocimiento científico.

${ }^{4}$ Por pura casualidad esa $s$ (añadida porque se pensó en la correspondencia été-estio) no resulta un disparate: es que también existe $s$ en el verdadero linaje, es decir, en el de a e s t u a ri u m.

${ }_{5}$ Y está evidentísimo en el Dicc. Acad., el cual desde la 12 a ed. (1884) definía así: "Estiaje. (De estio). Nivel más bajo o caudal mínimo que ordinariamente tienen las aguas de un río, o de otra corriente, por efecto de los calores del estío". Sin duda algún técnico advirtió el error, pues desde la $15^{\text {a }}$ ed. (1925), aunque la etimología sigue siendo errónea (del fr. étiage, y éste del lat. aestivaticus), la definición ha sufrido radical reforma: "1. Nivel más bajo o caudal mínimo que en ciertas épocas del año tienen las aguas de un río, estero, laguna, etc., por causa de la sequía./ 2. Período que dura este nivel bajo". Creo que podría aún reformarse la primera acepción con no mencionar la causa, o si no, redactando así: "por causa de la sequía o de los hielos", estos últimos, de gran importancia en las corrientes de origen alpino. 
La confusión en portugués había de ser aún mayor pờ el hecho de existir en esa lengua el verbo estiar que, como hemos adelantado, tampoco tiene nada que ver con estio.

El verbo estiar 'dejar de llover' vive también lozanamente en el actual gallego-asturiano. Yo lo he recogido y comprobado muchas veces en los tres Oscos (Santa Eulalia, San Martín y Villanueva ${ }^{6}$ ), siempre con ese sentido de 'cesar de llover, escampar': la pronunciación en Santa Eulalia (al lado del límite de Lugo) oscilaba entre estẹar y estiar; en algunos puntos del gall. del Este de Lugo se oye estẹar; en el gallego-asturiano de los otros dos Oscos, estiar: "Sei que paróu de chober: ša'stiọu" (San Martín de O.) 'Me parece que ha dejado de llover: ya ha escampado'. También en San Martín, estiada 'clara': "Se bęy úa estiada ..." 'Si viene una clara ...'

En ACEvedo y Fernández se encuentra estiarse como sinónimo de aveirarse, es decir 'ponerse al resguardo de la lluvia', como término de Coaña. Es cierto que dentro del gallego-asturiano hay una zona donde estear o estiar significa 'guarecerse de la lluvia'. Esa zona no debe de ser, sin embargo, muy extensa: no alcanza, como hemos visto, a los Oscos (allí 'resguardarse de la lluvia' se dice abeirarse ${ }^{7}$ ); MENÉNDEZ García, que ha delimitado escrupulosamente la frontera oriental de $-n$ - caediza, desde el Norte (alrededores de Villapedre) hasta el Sur de Asturias (entre Ibias y Degaña), ha encontrado siempre, en el Norte y en el Sur y en el centro de esa línea, del lado ga-

${ }^{0}$ Nombres oficiales. Los verdaderos son: Santalla, Samartín y Bilan ${ }_{Q}$ ba de $\mathrm{Q}^{\mathrm{sc}} \mathrm{O}$ s. Estos nombres designan a la par a tres concejos y a los tres pueblos en los que radica la capitalidad. Los tres están en el extremo occidental de Asturias. Santa Eulalia y Villanueva lindan con Galicia (Lugo); y con los dos, San Martín. Lo mismo que otros concejos del Occidente de Asturias, hablan gallego-asturiano, dialecto básicamente gallego con algunos fenómenos del asturiano. El desgracia. do título que al juntar los Vocabularios de Acevedo y Fernández se puso en el Centro de Estudios Históricos al libro (Vocabulario del bable occidental) ha hecho que varios investigadores llamen a estas hablas "bable occidental": es un nombre que no produce sino confusiones con el "asturiano occidental", que es otra cosa distinta. Sólo el nombre de "gallego-asturiano" define bien a este dialecto, hablado en Asturias, sí, pero que tiene en común con el gallego no sólo

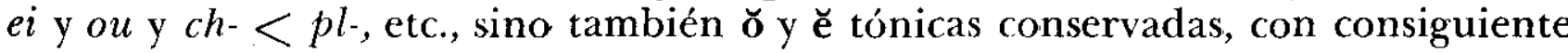
diferenciación etimológica de o y 0 , e y e, con metafonía verbal (muy semejante a la portuguesa), con infinitivo conjugado, con pérdida de - $n$ - (mientras que $-l$ - se conserva en general, aunque se pierde en bastantes palabras). Véase $R D T P, I, 1945$, págs. $43^{0}-43^{1}$ y $43^{\circ}$, nota 4 ; II, 1946, pág. 10 , texto y nota 24 bis; RFE, XXVII, 1943, pág. $15^{6}$, nota 1 . El límite oriental del gall.-ast. con el ast. occid. está claramente definido por la línea hasta donde llegan (con ligeras diferencias) dos fenómenos gallegos: la pérdida de - $n$ - y la no diptongación de ŏ y $\breve{~}$ tónicas. Véase ahora el artículo de Manuel Menéndez García, "Algunos límites dialectales en el Occidente de Asturias”, BIEA, V, 1951, págs. 259-275.

${ }^{7}$ Hay que tener en cuenta que, en la región, beira 'extremo u orilla', signi. fica especialmente 'alero del tejado'; beiras se llaman las losas o pizarras del alero. No consignan esto último AcEvedo y Fernández; lo he recogido en los Oscos y en el concejo de Castropol. 
llego-asturiano (es decir, de - $n$ - perdida), estear 'dejar de llover' y correspondientemente, del lado del asturiano occidental (de - $n$ - conservada), estenar con el mismo sentido. También Álvarez nos acredita estenar 'despejar el cielo' como leonés de Laciana. Sin embargo, yo que recorrí años antes una parte del mismo límite completado ahora por Menéndez García, había recogido estenar 'resguardarse de la lluvia' y con el mismo sentido estiar en Loredo (barrio de Ponticiella $^{8}$ ) y estear en Oneta ${ }^{9}$. En resumen, la zona de estear, estiar 'resguardarse de la lluvia' no se limita a Coaña, en el gallegoasturiano (único dato de Acevedo y Fernández), y además se prolonga con una de estenar 'resguardarse de la lluvia', dentro ya del asturiano occidental.

Atraigamos aquí otros verbos asturianos que significan 'dejar de llover', como (a)bocanar (RATO) ${ }^{10}$ y (a)bellugar (JUNQUERA Huergo,

${ }^{s}$ Al Sudoeste de Villayón, y al Este de Ponticiella. Ponticiella está muy cerca de la orilla Este del Navia.

- Al Nordeste de Villayón. Oneta es punto litigioso entre el gallego-asturiano y el asturiano. Visité la región en 1944: “... toda la larga parroquia de Ponticiella [ia pesar de su nombre!] ... tiene netas condiciones gallego-asturianas. No así Villayón y Oneta, en donde la caída de - $n$ - es quizá el único rasgo gallegoasturiano" (D. Alonso, "El saúco entre Galicia y Asturias", RDTP, II, 1946, pág. 10, nota 24 bis). Véase ahora el citado artículo de M. MenÉndez García. Caracteriza también a esta zona (Villayón, Oneta) la no diptongación de $e$ y $o$ ante nasal. Los datos de Menéndez coinciden con los de mis interrogatorios, aún inéditos, desde luego en estos rasgos fonéticos. En cuanto al sentido de estear, vista la divergencia entre el recogido por Menéndez 'dejar de llover' y el que oi yo 'resguardarse de la lluvia', pienso que probablemente coexistirán allí los dos.

${ }^{10}$ El tipo abocanar 'dejar de llover' tiene gran extensión. Está registrado como (a)bocanar en Santander (García Lomas) y es, básicamente, el (a)bocanhar que como trasmontano y miñoto traen los diccionarios portugueses. Figueiredo interpreta 'diz-se do tempo que se alivia nos dias de chuva; fazer bocanho'. Bocanho es, como la bocana del asturiano (RATo) y del santanderino (García LoMAs, también escampa), la 'clara' o 'escampada' (port. aberta) que sigue a la lluvia. Bocana es en muchos puertos españoles la entrada o boca que queda como acceso entre dos espigones. Conocida es la Bocana de la Mar Chica (Melilla). Es curiosa la variada metaforía de que la lengua ha echado mano para la idea de 'cesar de llover': dejando aparte las que trato en este artículo, unas veces es la luz lo predominante, como en el esp. aclarar (REW, 1963), en el gall. delampar (REW, 4870 ), quizá en el asturiano abellugar abiŝ̀ugar, que creo que puede tener el mismo origen que el prov. belugar, beluguejar 'étinceler' (REW, 1127); otras veces es el abrirse de las nubes lo que se ha tenido en cuenta: esp. abrir, ast. abocanar, port. abocanhar, quizá el salm. y arag. alambrar (véase RFE, XXVII, 1943, págs. 32-33); otras, se ve ese abrirse como una desacumulación o desmontonamiento de las nubes: gall. esbardar (gall. barda 'montón', $R E W, 955$ ), jurdano escumbrar $(R E W, 2390)$; otras, el cielo que abre se compara con un campo raso y sin obstáculos: esp. escampar, ponerse raso, arrasar, jurdano escarrampar, escarramplar; esp. despejar, gall. arrazar; otras, son verbos derivados de b o n u s, como esp. abonar, abonanzar. Entre estos grupos de verbos hay originarios matices de significado, pero todos pueden sustituirse, y constantemente se sustituyen en la imprecisión del habla. 
Canellada). Ocurre que estos dos verbos significan también a veces 'guarecerse de la lluvia'. Hay sitios donde el único significado es 'guarecerse de la lluvia': así abiŝ̀ugar, forma del ast. occid., correspondiente a abellugar, que he oído en Otur ${ }^{11}$ y usada con el mismo valor en Cangas de Narcea, según me informa Rodríguez Castellano. Hay otros lugares donde tienen ambos significados; así sucede en Cabranes (CANellada). Son, pues, tres los verbos donde (por lo menos en algunos sitios) se dan los dos significados 'dejar de llover' y 'resguardarse de la lluvia': estiar (estear, estenar), abocanar y abellugar. Si ahora consideramos el caso de estiar, hemos de reconocer en seguida que en él la acepción 'resguardarse de la lluvia' es secundaria. En efecto, entre el gallego-asturiano y el portugués se completa una inmensa área (que en algún tiempo, hemos de imaginar, fué continua) donde estiar (estear) significa 'dejar de llover' (prolongada aún en el asturiano occidental con estenar). No cabe duda de que ésta es la acepción primaria. Pero en algunos sitios se dió el fácil paso del impersonal 'dejar de llover' al personal 'guarecerse donde no llueve'.

La existencia de estenar en la zona del asturiano occidental donde - $n$ - se conserva mientras que a pocos kilómetros (a veces, hectómetros), donde comienza la pérdida de -n-, se encuentra estear, estiar, prueba, sin necesidad de más argumento, que el port. estiar no tiene nada que ver con a e s t i v u m. En la etimología de estiar no puede haber una $-v$-; lo que tiene que haber es una $-n$-. La forma básica que postulan todos los representantes actuales es * e s te n a re. Y el único verbo latino que la proporciona directamente es ex te $\mathrm{n}(\mathrm{u})$ a r e 'adelgazar, debilitar, disminuir, decrecer'. Estiar no es sino 'disminuir, debilitarse, decrecer la lluvia'. Recuérdense los valores semánticos de escampar en frases como está escampando; parece que ya escampa.

El $R E W$ (3085) señala sólo un derivado logudorés de e x t e$\mathrm{n}$ u a r e, el log. astenare. En los representantes gallego-asturiano, gallego oriental y portugués, al caer la $-n$-, la $e$ queda en hiato (estear, forma del gallego oriental que también se halla en bastantes puntos del gallego-asturiano). Pero en el hiato la $e$ dió $i$, de donde gall.-ast. y port. estiar ${ }^{12}$. Compárese en portugués arear, areal, cear (castellano enarenar, arenal, cenar), formas que la ortografía fijó así, pero cuya pronunciación (por lo que toca a las vocales en hiato) es ariar, arial y ciar. Si en estiar la pronunciación se impuso a la ortografía, se debe, sin duda, a que esta palabra vivió mucho tiempo en medios populares

${ }^{11}$ Añádase, en Somiedo, ablogar 'cobijarse', que debe estar en relación directa con abellugar.

${ }^{12}$ Los diccionarios portugueses (CAldas Aulete, Figuliredo) traen también estear 'amariçar o gado'. No tiene nada que ver aquí: es mera variante de sestear. Comp. salm. (a)marizar 'sestear el ganado' (LAMANo). 
(comp. criar $<\mathrm{cr} \overline{\mathrm{e}}$ a r e $)^{13}$ antes de ser recogida por la lengua culta, y cuando entró se había perdido todo recuerdo de su vinculación etimológica; se la ligaba erróneamente a estio. En cuanto a lo que ocurre en el gallego-asturiano, donde en unos sitios tenemos estiar y en otros estear (y aun con oscilaciones en un mismo lugar y sujeto), compárese con lo que sucede con los representantes de c e n a re, c e n a, cat e na y p le na: en los Oscos tenemos estiar, ciar ${ }^{14}$, cia, cadia y chia, pero en zonas del gall.-ast. occidental hay vacilación y se encuentra a veces estear, cea, cadea, chea, sin que haya perfecta regularidad en las correspondencias.

Al lado del gall.-ast. y port. estiar, del gall. oriental y gall.-ast. estear, y del leon. (ast. occid.) estenar, existen todos los correspondientes deverbativos: leon. esteno 'claro, despejado' (Alonso Garrote), gall. oriental esteo, gall.-ast. estén 'escampado' ("ša nun chọbe: ša ta'stęy" 15̃), port. de Madeira esteio, que Figuerredo hace equivalente de estiada, es decir, 'tiempo sereno después del lluvioso'. Todas estas voces significan '(cielo) escampado' o '(tiempo) escampado', es decir, en todas existe un valor participial como en cast. lleno (=llenado), gall.-ast. šebre (= ̌̌ebrado). La correspondencia fonética es perfecta; confróntese con los derivados de p l e $\mathrm{n} \mathrm{u} \mathrm{m} \mathrm{:}$

$\begin{array}{llll}\text { leon. (ast. occid). estenar } & \text { esteno } & \text { ĉenù }{ }^{16} \\ \text { gall.-ast. } & \text { estiar } & \text { estén } & \text { chen } \\ \text { gall. orient. } & \text { estear } & \text { esteo } & \text { cheo } \\ \text { port. } & \text { estiar } & \text { esteio } & \text { cheio }\end{array}$

Surgen ahora complicaciones. Al lado de estiar, los diccionarios portugueses (Caldas Aulete y Figueiredo) traen como trasmontano estinhar, con el sentido de 'dejar de llover', y como miñoto la misma voz con el significado de 'dejar de correr el agua'. Pero que estinhar en miñoto significa también 'dejar de llover' lo acredita esta coplilla (citada por Cunha Brito en su "Etnografia minhota", $R L u, \mathrm{XV}$, 1912, pág. 304), en la que 'stinhar se da como equivalente de abocanhar:
Abocanha, abocanha, que te dou ũa castanha!
'Stinha, 'stinha, que te dou ũa sardinha!

(Coplilla infantil para que deje de llover). Carré da como formas

${ }^{13}$ Para la $e$ en hiato ante -ar, véase Nunfs, Gram. hist. port., $\$ 34 b$.

14 Ciar vive casi exclusivamente (como ya indican Acrvedo y Frenándfz y yo he podido comprobar en toda la zona) en el recuerdo de los más viejos. Ha sido sustituído por el castellanismo cenar. Algo semejante ocurre con cía, que vive en el refrán "en casa chía (l)lougo se fai a cía".

15 estến: la nasal trabante abre la vocal anterior en el gall.-ast. de los Oscos.

16 La forma ĉenų, en el leon. de Laciana (Álvarez). 
gallegas estiñar 'detener el curso de la sangre u otro líquido' y estiñir 'dejar de caer agua', 'cesar de llover'. Para este estiñar propuso precisamente Connu la etimología e x t e $\mathrm{n}$ u a r e que nosotros proponemos para estiar. ¿Sería, pues, estiñar una nueva forma de la misma familia a que pertenece estiar?

El proceso -ẹná->-iñá-, admitido por Williams ( $\$ 78_{4 c}$ ), no es nada seguro: estaría basado sólo en ordinhar, verbo del que hay abundantes ejemplos en algunos textos ( $R L u$, XXVII, 1928-29, pág. 55), junto a ordĩar y a ordĩ 'orden'. Pero este ordinhar 'ordenar en lo eclesiástico', a juzgar por su sigríficado y por los textos en que aparece, no ha tenido una evolución popular ${ }^{17}$. Frente a él existen cear $<$ c e n a re, refrear $<$ refre na re, alhear $<$ a l i e $\mathrm{n}$ a r e, nomear $<\mathrm{n}$ o m i n a r e, (a)meaşa $<$ (a d)m i n a c i a, y al lado ameaçar, sin que la evolución haya llegado a desarrollar $-n h$-. Del lado fonético no resulta, pues, favorecida la hipótesis de que estinhar venga de e x t e $\mathrm{n}$ u a r e. Ocurre además que frente a la gran fijeza del significado fundamental de estenar, estear, estiar 'dejar de llover', estinhar significa en port. miñoto 'dejar de correr el agua' (FigueIredo) y también, como hemos probado, 'escampar'; y estiñar, en gallego 'restañar'; 'estancar o detener el curso de la sangre u otro líquido' (CARré). $\mathrm{Si}$ esos datos son exactos, hay amplias zonas en las que el sentido de estinhar es muy distinto del de estiar. CARré nos da el verbo estiñir, que volvería a reunir el sentido de 'dejar de caer agua', 'secarse una fuente' y 'dejar de llover'18. Todo esto es confuso. Para estiñir se piensa en seguida en ex sting u e re, que tiene acepciones próximas (exstinguere aquam riuis; sucum, etc.), como también las tienen los derivados románicos de $\mathrm{s} \mathrm{ta} \mathrm{g}$ a $\mathrm{r}$ e. Entre los representantes de

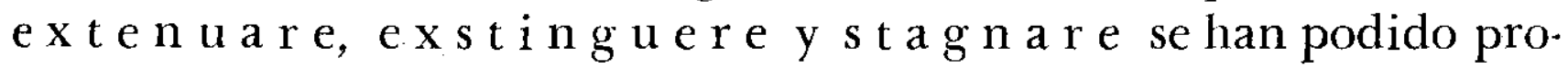
ducir toda clase de cruces y confusiones: pretender seguirlos en pormenor sería pueril.

Lo que sí es evidente es que el port. estiar no tiene nada que ver con estio, como tampoco tiene que ver estiagem: estas tres palabras con tres etimologías diferentes, estaban, sin embargo, irremisible-

${ }^{17}$ Otros ejemplos portugueses que cita Williams, ibid. (o que pueden ser citados) de desarrollo de $\tilde{n}$ en el hiato producido por pérdida de - $n$ - tras vocal $e$ o $i$ no acentuada, son: dinheiro (pero aquí la base es $* \mathrm{~d}$ in a $\mathrm{r}$ i u, comp. esp. dinero); port. dial. y gall. vinhera, viñera (pero es evidente consecuencia de un complejo proceso analógico); adivinhar $<\mathrm{d}$ e vīn à $\mathrm{r}$ e (pero aquí el punto de partida es -iná- y no -ẹná-, y además las formas fuertes y los sustantivos adivinho, adivinha, justifican la $\tilde{n}$ ). Hay, en fin, gall. aviñeira, junto a vieira ( $<\mathrm{v}$ e n e $\mathrm{r}$ i a, esp. venera); comp. port. vieiro $<$ v e $\mathrm{n}$ a $\mathrm{r}$ i $\mathrm{u} \mathrm{m}$.

${ }^{1 *}$ Téngase en cuenta, además, el salm. estino 'el estrellado del cielo', según Lamano, que debe considerarse, creo, como un deverbativo (¿de estiñar? ¿de estiñir?). Comp. los deverbativos de estenar, estear, estiar citados antes en el texto. La forma esperable * estiño, sentida como portuguesismo, habría sido castellanizada en estino, según la correspondencia de caminho y camino. 
mente condenadas a despistar a los etimólogos, a convertir en falsificadores de acepciones a los lexicógrafos y, en fin, a entrelazarse también en la mente de cualquier hablante. Así a estiagem le van naciendo acepciones basadas de un lado en estio y de otro en estiar. Así se origina la acepción de estiagem 'tempo sereno ou sêco, depois de tempo chuvoso ou tempestuoso', que figura en Caldas Aulete, y que en Figueiredo queda ya -pintorescamente-como único significado.

\section{GALL. AST. BEDRO 'ESTIVADA'}

En los Oscos las labores son de dos clases: en las pęzas o terreno mansọ se labra el pạj ${ }^{19}$ llamado d'estib ${ }^{20}$ o de mansọ. Las pęzas son tierras labradas continuamente por sus propietarios; con frecuencia forman bilares $^{21}$ junto a los pueblos.

Pero el monte ${ }^{22}$ es de todos. Cada vecino escoge allí el sitio que le parece apropiado. Lo cava entre mayo y junio, y en agosto quema los tọrrois: bien haciendo burruẹiras ${ }^{23}$, que son montones de tọrrois, con lo que se facilita el tiro del fuego; o bien los torrois se queman a un lume $^{24}$ tal como han quedado sobre el terreno después de la cava: "No mes de setięmbre ẹso que se quẹima a burruẹiras estę́ndese $\mathrm{cu}^{\text {n }}$ os rodalos qu'ái de fęrrọ. El que se quẹima'un lume ša tá" ${ }^{25}$.

$\mathrm{Al}$ deshacerse las burruẹiras las cenizas esparcidas sobre el terreno le sirven de abono. Falta sólo labrar y sembrar el trozo de monte ro-

${ }^{19} P a_{1}$ 'centeno'. Pero se siembra también algo de trigo.

${ }^{20}$ Estib $_{\mathrm{O}}$ 'tierra de labor que se cultiva continuamente'. Es lo mismo que peza. Un sujeto de Santa Eulalia decía pan d'estib $b_{0}$, otro de San Martín pay estibọ. He aquí la definición del último: "Pạ estibọ ę́l pan das caserias, el pạ que se labra nas pęzas; el del monte é będrọ". El pan d'estibọ es de dos clases: grandal y serodo; este último se siembra en marzo.

${ }^{21}$ Un bilar es un 'conjunto de fincas o tierras de labor, contiguas y que tienen servidumbres comunes'. Frecuentemente está el bilar junto al pueblo. Así en San Martín (REW, 9332).

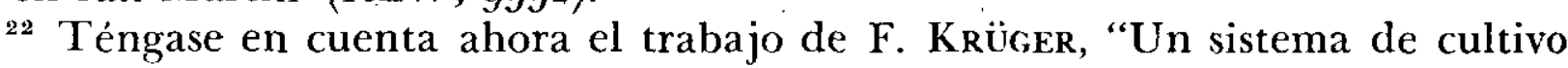
arcaico: la quema del monte", $N R F H$, IV, 1950, págs. 231-246. Antes, en $V K R$, V, 1932, pág. 105, nota 8, EBELING había señalado y dado las características esenciales de este tipo de cultivo. (Llamo a estos trabajos Krüger y EBELING, respectivamente).

${ }_{23}$ En Agevedo y Fernández, barrueiras; en el Este de Lugo burrueiras (EbE-

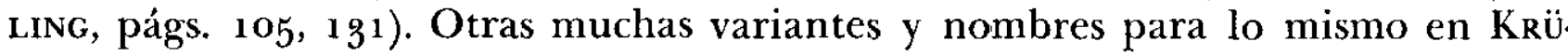
GER, págs. 234-239.

${ }_{24}$ Es, evidentemente, lo que Krüger llama arder a por pé (cf. Ebeling, pág. $10_{5}$, nota 8 ). Un sujeto de Santa Eufemia de Oscos llamaba a esto mismo queimar da faz ou al lume.

${ }^{25}$ Setięmbre es castellanismo; ẹ $s_{\mathrm{O}}$ que = 'lo que'; rodalos son una serie de instrumentos que sirven unos para el horno, otros para limpiar la cuadra (rebar a $c_{\mathrm{O}} r t e$ ), etc. (cf. $r_{\mathrm{Q}} d_{\mathrm{O}}$, en EBEling, pág. 131); el que = 'lo que'; queima' un lume =queima a un lume; ša tá 'ya está (esparcido de por sí)'. 
turado: "A últimos de setięmbre y a primẹiros d'outubre é cuandọ se labra ẹse pay que se chama de będro ou de siara ou de cinza".

Dos clases, pues: pan d'estibọ o de mansọ, de un lado; y del otro el pay del monte, llamado de będrọ o de siara o de cinza 'ceniza' (también de una chica soltera que ha dado un mal paso dicen que "tẹbo un fillọ de będrọ").

El sujeto informante, Joselín dos Amiẹiros, insiste aún: "El będrọ y a siara aquí é a misma cọusa: $\mathrm{u}^{\eta_{i}}$ os chamámoslle a siara y ọtros el będrọ".

El monte que se labra tiene un largo descanso. Después de cultivado un año puede dar aún pan al año siguiente: es lo que se llama restrẹbar; restrẹba ${ }^{26}$ es el terreno del monte en el segundo año de cultivo; de ahí también pan de restrẹba ("Dęucho" tan bọn estanọ de restrẹba comọ entanọ de cinza!"). Algunas veces, en buenos terrenos, se seguirá labrando ese trozo del monte algunos años más. Pero luego hay que abandonarlo a la gran naturaleza, para su eterna obra: plantas y arbustos volverán a crecer allí; y han de pasar muchos años (quince, treinta ...) ${ }^{28}$ hasta que un labrador vuelva a zarrar $^{29}$ para sí aquel pedazo de monte ("No mọte unde’l terreno ${ }^{30}$ é ruín, tęy que pasar trint'anọs; outros terrẹnọs pódense cabar aus catọrce ou quince. Aọ́ra ${ }^{31}$ colo guanọ pódese labrar mais ašina").

La palabra będrọ es muy interesante. Conocidos son los nombres románicos de la estivada (al. Brachfeld ${ }^{32}$ ) que proceden, ya de

${ }^{20}$ Figuran estas palabras con sentidos próximos en los diccionarios gallegos: Cuveiro: resteba o restreba 'la segunda cosecha que se coge en un mismo terreno'. VALladARES: resteva o restreva (tèrra de) 'tierra que está de rastrojo o en que se segó centeno, cebada, trigo, mientras no se siembra en ella otra cosa’; restevar, restrevar 'barbechar, dar la primera labor de arado o de azadón a una heredad, disponiéndola para la siembra'; restrevar 'concebir pronto la hembra de cualquier animal' (entiéndase, poco tiempo después de un parto anterior; así por lo menos lo he oido en Lugo); restreveira, restreviza 'rastrojera'. CARRÉ: restreva 'campo de rastrojo'; restrevar 'roturar una restreva'.

${ }_{27}$ 'Te lo dió, te lo ha dado'.

${ }^{28}$ De diez a veinte años, según Ebeling, pág. 105, nota 8. Seguramente hay muchas variaciones locales, según la calidad de los terrenos.

${ }^{29}$ C.f. Acevedo y Fernández, s. v. zarrar.

30 Castellanismo muy extendido. La forma legítima es terrén o tarrép.

${ }^{31}$ Así este sujeto de Santa Eulalia; otros, de San Martín, aóra.

"22 Uso estivada en la acepción única del Dicc. Acad.: 'monte o terreno inculto cuya broza se cava y quema para meterlo en cultivo'. Pero hay que estar preparados a admitir estupendas fluctuaciones locales del significado de todas estas palabras, fluctuaciones que, como señalo en el texto, para los derivados de "s o m a ro (pág. 168), pueden ir desde 'yermo' hasta 'tierra de labor', a través de 'estivada', 'barbecho' y 'tierra preparada para sembrar'. Oscilaciones semejantes, más o menos intensas, aféctan a barbecho, a friche, a jachère. Es que los usos agrícolas tienen mil matices intermedios: por estos matices intermedios puede ir resbalando una palabra de un significado en otro hasta dar en uno contrario al inicial. También hay, creo, fluctuación en el alemán Brachfeld que los diccio- 
v ět $\breve{\mathrm{u}} \mathrm{s} \mathrm{t}$ u s, como el boloñés bdost; ya de v ĕ t ŭ s, como el veneciano vegro, el friulés vieri, lionés viero, francés del Sur veiro; ya de $\mathrm{v}$ ĕ tĕ rn u s, como el istrio vedorno (cf. $R E W, 9289,9292,9293$ ).

En port. y gall. antiguos es bien conocido vedro 'viejo' ${ }^{33}$, que también ha dejado numerosos descendientes en la toponimia, aunque la confusión de $\boldsymbol{v}$ - y $b$ - haya hecho que algunos de los topónimos gallegos no se hayan tenido en cuenta. En Portugal Tôrres Vedras, y Alhos Vedros ${ }^{34}$ en Galicia, Pontevedra, Pardavedra, Saavedra, Casavedra, Eiravedra, Eirasvedras, Bustovedro, Fuentevedra (sic, Lugo), Vedra (Coruña), Vedro (Salvatierra, Pontevedra), Bedro (Puertomarín, Lugo), Vedros (Alfoz, Lugo, en Madoz con $B$-), Vedrelos (Mondariz, Pontevedra), Torre-Vedra (dos pueblos, Pontevedra), RozasVedras (Lugo), Mombiedro (Valladolid; comp. Montenovo, Lugo) ${ }^{35}$. En perfecta correspondencia, la toponimia catalana da Estalavedra, Alavedra, Vilavedra, la Vedra, Vedro ${ }^{36}$.

Dada la constancia y extensión románica de las formas con -o, podría pensarse en una declinación vulgar ${ }^{*} \mathrm{v}$ e $\mathrm{t}$ ĕ $\mathrm{r} u \mathrm{~s},-\mathrm{a},-\mathrm{u} \mathrm{m}$ (cf. Grandgent, § 376). Pero los fenómenos analógicos de este tipo pueden también producirse separadamente y en diversas épocas.

Recordemos ahora que en los Oscos będrọ y siara son una misma cosa. Recientemente Johannes Hubschmid ha publicado un serio estudio sobre la $\mathrm{a}_{\mathrm{s}}$ palabras peninsulares senera, seara, senra, serna $(B d F$, XII, 1951, págs. 117-154). En él combate la hipótesis de Jud y Aebischer (ARom, V, 1921 , págs. 51-52), según la cual la significación.fundamental del port. y gall. seara habría sido también 'jachère', 'barbecho'. En s e n a r a, base etimológica de estas palabras, veían Jud y Aebischer un representante de la raíz céltica s e n - 'viejo' (correspondiente céltico del lat. s e n-e x, s e n-ē re, etc.) y, naturalmente, les servía de muy buen coadyudante para su idea el gran número de representantes de v ět u s, v ět u s t u s, etc., que en lenguas románicas significan 'Brachfeld'. La prueba aportada en contra por

narios unas veces traducen 'friche' y otras 'jachère'. Barbecho tiene también variaciones de significado. Me atengo a la Academia que lo define 'tierra labrantía que no se siembra durante uno o más años' (el uso castellano es la siembra un año y el descanso uno o dos). En cambio el $b$ ędro habría que definirlo 'terreno de monte que se labra uno o unos pocos años, y se abandona luego de nuevo a monte'. A barbecho corresponde aproximadamente el fr. jachère; y al cast. estivada, el gall.-ast. będro y el fr. friche. Cf. ARom, V, 1921 , pág. 34 .

${ }^{33}$ Cf. Nunfs, RLu, XXVII, 1928-29, pág. 76. Es frecuente en documentos gallegos.

${ }^{34}$ Sobre Alhos Vedros, véase Piel en RPF, IV, 1951, págs. 215-219.

${ }^{35}$ Datos de MAdoz y del Nomenclátor. Deben de pertenecer aquí Bedral y Bedreiros, pero hay que tener cautela ante posibles representantes enmascarados del $R E W$ 1068, gall. bidueiro, gall.-ast. bidueira, budueira, biduro, bidrueiro, etc., formas recogidas por mí. En ACEvEdo y FERNÁNdez bidureiro.

${ }^{36}$ Corominas, $B D C$, XXIII, 1935, pág. 325. Murviedro es evidente castellanización. 
Hubschmid es principalmente documental (ejemplos medievales de senera, senra, serna, senara, y aún podrían haber sido muchísimos más); lo que Hubschmid no hace -y sería dificilísimo hacerlo- es, mediante una crítica rigurosa, delimitar el sentido que en cada caso tiene cada una de estas palabras. Porque ¿qué quieren decir sernas, senras cuando el documento distingue "terras et senras"? ¿qué en la expresión "in sernas, terras, in vineas" o en "cum sernis et bustis de monte Pelio", o en "sernas, terras cultas et incultas", etc.? ¿Qué oposiciones o delimitaciones conceptuales quisieron expresar los redactores de esas frases? Habría que atraer muchísimos más ejemplos, tener en cuenta las muy distintas regiones, estudiar las sustituciones o presumibles equivalencias de las fórmulas jurídicas, anotar la presencia y la ausencia, no sólo de senras, sino de cada una de los términos de esas enumeraciones notariales.... y después de todo ese trabajo, dudo mucho que se llegara a una imagen clara.

Una cosa es cierta: en este rincón -en tantos aspectos arcaizantede los Oscos, będrọ y siara significan lo mismo: 'estivada', 'Brachfeld'. Lo significan con un especial matiz que explica perfectamente el sentido de będrọ: nada más 'viejo' que ese campo, perdido en el monte, abandonado un cuarto de siglo ( $\mathrm{y}$, a veces, bastante más) a la invasión del monte, ese campo que quizá los hijos o los nietos del antiguo cultivador volverán a cavar un día... Vemos, pues, que el sentido general de $b e ̨ d r o ̣$ se ha especificado y sustantivado directamente al pasar a designar un trozo de tierra labrado una vez cada cuarto de siglo.

¿Habrá ocurrido lo mismo con siara? Si fuera así, Jud y Aebischer tendrían razón. Pero no podemos sacar consecuencias apresuradas. Contra lo que se pensaría a primera vista, nada más cambiante que los sentidos de una voz empleada para designar una compleja serie de operaciones que tienen mil matices entre la práctica de la cinza (tal como se ha descrito en este artículo), con su posible restrẹba, y la del barbecho de un año, a la manera cerealista castellana, matices que pueden complicarse aún con otros procedentes de la rotación continua de cosechas (tal como se practica, por ejemplo, en los mismos Oscos en las pęzas de los bilares) ${ }^{37}$.

¿Cómo, si no, explicar que junto a la voz gallega y castellana est $i$ vada (< a e s t i v a t a) - con muchas correspondencias en el Sur de Francia $^{38}$-, empleada para designar un cultivo más o menos parecido al de los będrọs, en los propios Oscos se emplee, como hemos visto,

${ }^{3 \top}$ He aquí esta rotación referida por un sujeto (algo castellanizante) de una

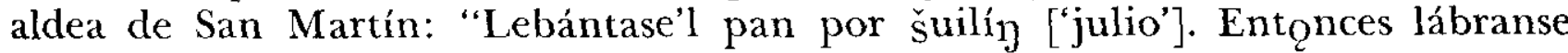
nab $_{O}$ s por agosto. Quedan us nab ${ }_{O} s$ na tęrra asta marzo y abril. Ent ${ }_{Q}$ nces lábrase el maiz y as patacas (antes as patacas que'l maiz), e bolbe'l pay".

${ }^{38}$ ALF: éstibat, 684, 685 (Landes y B.-Pyrén.); stsivadz, 807 (Puy-de-D.); etyuvedo, 809 (Puy-de-D.) ; estyivadza, 811 (Cantal); estyivada, 812, 813, 815 (H.Loire); etyivalo, 817 (H.-Loire); estyivado, 824 (Ardèche). La vitalidad de la pala- 
la palabra estibọ en el mismo sentido que mansọ, es decir, para designar el terreno de las pęzas con su rotación continua de cosechas? Si se quiere una prueba de esta fluctuación de acepciones, basta ver la variación de las de algunos derivados galorrománicos de *s o $\mathrm{m}$ a $\mathrm{r}$ o , acumulados por Jud y AEBISCHER: en Yonne, sombres son 'terres non ensemencées, où l'herbe a poussé spontanément'; en Saboya, somâr 'champ en friche'; en Fourgs, souma 'terre nouvellement labourée'; en fr. ant. somart 'jachère, terre labourable en friche'; y hoy en Gruyère, chombero 'champ prêt à être ensemencé', y en Leysin, xomor 'champ labouré' ${ }^{\circ}$. Vemos, por tanto, que en el ambiente semántico en que nos movemos, una misma voz ("misma" en lo fundamental) puede -a través de muchos sentidos intermediosdesignar en sitios distintos conceptos absolutamente contrarios: en una parte 'tierra yerma, no cultivada' y en otra 'tierra de labor'. Pero esto ha podido pasar con $\mathrm{s}$ e $\mathrm{n}$ a $\mathrm{r}$ a , como vemos que casi pasa ante nuestros ojos con estivada y estibo.

Hay una acepción todavía entre los derivados de *s o ma ro que tiene interés para nosotros: en Blonay sonbéro significa 'bande de gazon bordant un champ'. Ahora podemos plantear el problema de la única acepción sustantiva de vedro que registran los diccionarios portugueses: 'comoro ou sebe com que se cercam ou circumvallam os campos de lavoira' (CAlddas Aulete), y 'valado', para FigueiREDO, quien agrega: "relacionam-no geralmente com vedro 1 [es decir, el adj. procedente de vě t u s], não sei porquê". Como vemos por el anterior ejemplo galorrománico, del concepto 'yermo, sin labrar', se puede pasar al de 'margen o marco de hierba que rodea una tierra de labor'; que de este último se pasa fácilmente al de 'vallado o seto' lo prueba sin más el gallego y portugués comareiro, en gall. 'faja de tierra que se deja sin cultivar alrededor de una heredad labrantía' (CARré), en port. 'muro que sustenta terreno de socalco' (FigueireDo), donde ya se está bien cerca del simple concepto 'muro'^o. Hay todavía otro camino, y aun más directo, por donde vedro 'valado' resulta explicable: los będrọs se cierran en algunas partes de los Oscos: "A siara ai que zarrala. Aquí [en Santa Eulalia] tẹmos ẹsẹ costumbre ${ }^{41}$. Por ajęmplọ ${ }^{42}$ en Samartín ša tẹin el costumbre de deišalas abęrtas.

bra en Galicia está acreditada por el gran número de topónimos Estivada y Estivadas (Lugo, Orense, muchos en Pontevedra).

${ }^{39}$ Citados por Jud y Aebischer, ARom, V, 1921 , págs. 32-34.

4) La variedad local, que los diccionarios ignoran, daría muchas más acepciones; y lo mismo ocurriría con el port. cômoro, gall. cómaro, cuyas definiciones suelen estar influídas por la etimología cu mŭ $\mathrm{lu}$, hoy poco sostenible después de la exposición de Hubschmid, art. cit., págs. 139-141. En la zona gall.-ast. caldullẹiro (o calduyẹiro) significa lo que comareiro en Galicia (caldulleiro se oye también en puntos del Este de Lugo).

«1 Castellanismo generalizado; pero conserva el género masculino.

${ }^{42}$ Castellanismo: jota castellana. 
En Santalla zárranse". Naturalmente que el nombre będrọ ha podido pasar, del terreno mismo, al cierre que en la soledad del monte le caracteriza, y, en fin, en algunos sitios, pasar luego a designar otros cierres, hechos del mismo modo, de otras fincas de labor. Así se podría explicar la acepción sustantiva del port. vedro que a Figueiredo le resulta inexplicable.

¡Cuánta fluctuación de acepciones! ¿Quién, ante el significado 'bedro' que siara tiene en los Oscos podría determinar si es una acepción antiquísima de s e n a ra, allí como tantas otras antigüedades conservada, o una mera ramificáción muy rebotada y local del sentido general de seara en gallego y portugués 'campo de trigo', 'terreno cultivado' (CARRÉ), 'terreno onde crescem cereais; terreno semeado; messe; campo cultivado; qualquer campo coberto de vegetação' (FIGUEIREDO)?

Quede, en fin, como lo único seguro la existencia en ese rincón peninsular de un compañero de los derivados de $v \breve{e} t \breve{u} s$, de vĕtŭstus, etc., que en otras partes de la Romania significan 'Brachfeld'; y el hecho curioso de que esa misma acepción que JuD y Aebischer supusieron fundamental en s e na ra y que HubschMID no encontró en sus derivadoss latino-románicos medievales, esté allí claramente representada en siara. Siara $=b e ̨ d r o ̣=$ 'Brachfeld'.

Dámaso Alonso

Madrid. 